\title{
Influencing factors of pneumothorax and parenchymal haemorrhage after CT-guided transthoracic needle biopsy: single-institution experience
}

\author{
Tunyarat Wattanasatesiri ${ }^{A, B, C, D, E, F}$, Warunyoo Puntu ${ }^{A, B, C, D, E, F}$, Nophadol Vithitsuvanaku ${ }^{A, B, E}$ \\ Department of Radiology, Faculty of Medicine, Thammasat University Hospital, Pathum Thani, Thailand
}

\section{Abstract}

Purpose: To evaluate the incidences and influencing factors of pneumothorax and parenchymal haemorrhage after computed tomography (CT)-guided transthoracic needle biopsy (TTNB).

Material and methods: A retrospective analysis of 216 patients who underwent CT-guided TTNB was performed. The frequencies and risk factors of pneumothorax and parenchymal haemorrhage were determined. $P$ values less than 0.05 were considered statistically significant.

Results: The incidences of pneumothorax and parenchymal haemorrhage were $23.1 \%$ and $45.4 \%$, respectively. Twenty-two per cent of patients with pneumothorax needed percutaneous drainage, but all patients with parenchymal haemorrhage had clinical improvement after conservative treatment. No procedure-related mortality was detected. Univariate analysis showed that underlying pulmonary infection, lesion size of less than $1 \mathrm{~cm}$, and lesion depth of more than $2 \mathrm{~cm}$ were significant influencing factors of pneumothorax. A significant relationship between the underlying chronic obstructive pulmonary disease (COPD) and the need for drainage catheter insertion was found. Pulmonary haemorrhage was more likely to occur in patients with underlying malignancy, solid pulmonary nodule, lesion size of $3 \mathrm{~cm}$ or less, and lesion depth of more than $3 \mathrm{~cm}$. Consolidation was the protective factor for pulmonary haemorrhage. Sensitivity, specificity, positive predictive values (PPV) and negative predictive values (NPV), and accuracy of CT-guided core needle biopsy (CNB) for the diagnosis of malignancy were $95.7 \%, 100 \%, 100 \%, 93.3 \%$, and $97.3 \%$, respectively. The rate of diagnostic failure was $10.2 \%$.

Conclusions: Pulmonary hemorrhage is the most common complication after CT-guided TTNB. Influencing factors for pneumothorax are underlying pulmonary infection, lesion size $<1 \mathrm{~cm}$, and lesion depth $>2 \mathrm{~cm}$. Underlying malignancy, solid pulmonary nodule, lesion size $\leq 3 \mathrm{~cm}$, and lesion depth $>3 \mathrm{~cm}$ are associated with pulmonary haemorrhage.

Key words: pneumothorax, computed tomography, accuracy, thoracic biopsy, pulmonary haemorrhage.

\section{Introduction}

Advances in computed tomography (CT) technology have resulted in increased detection of the smaller pulmonary and mediastinal lesions. According to the Fleischner Society 2017 guidelines for management of incidental pulmonary nodules detected on CT images, a solid solitary pulmonary nodule that is larger than $8 \mathrm{~mm}$ requires further work up of either three-month follow-up with CT, positron emission tomography/computed tomography (PET/
CT), invasive procedures for diagnosis, or a combination thereof [1]. The invasive procedures include transthoracic needle biopsy (TTNB) and transbronchial needle aspiration (TBNA), depending on the lesion locations and characteristics.

TTNB is a widely accepted procedure for definitive diagnosis of both benign and malignant lesions. TTNB can be performed under imaging guidance by several modalities including ultrasound, fluoroscopy, conventional CT, CT fluoroscopy, or cone-beam CT. Both fine

\section{Correspondence address:}

Tunyarat Wattanasatesiri, MD, PhD, Department of Radiology, Faculty of Medicine, Thammasat University Hospital, 95/8, Khlongnueng sub-district,

Khlongluang district, Pathum Thani, Thailand, 12120, e-mail: wtunyarat@yahoo.com 
needle aspiration (FNA) and core needle biopsy (CNB) can be obtained. FNA has high sensitivity, specificity, and accuracy for the diagnosis of malignancy, but it achieves definitive diagnosis of the benign lesion in less than half of the cases. CNB increases the rate of definitive diagnosis of the benign lesion to as much as $90 \%$ [2]. The reported range of the success rate of TTNB for pulmonary lesions is about $77-96 \%$ [3].

Pneumothorax and pulmonary haemorrhage are the two most common minor complications after CT-guided lung biopsy, ranging from $22.2 \%$ to $28.6 \%$ and $13.4 \%$ to $23.8 \%$, respectively [4]. The other complications are haemothorax, haemoptysis, and dyspnoea. In the reported cases, tumour seeding and air embolism could occur $[5,6]$.

Various factors contributing to these complications have been investigated, such as elderly patients, patients who have emphysema or bullae, deep lesion, small lesion, needle traversing emphysema or bullae, depth of needle traversing the aerated lung, needle traversing fissure, angle of needle with parietal pleura, size of the needle, coaxial or noncoaxial technique, rapid needle out, and rolling back [7-10]. The factors that were mostly stated in the previous literature are deep lesion, small lesion, presence of emphysema along the needle tract, and transfissural approach.

While there are many literatures references to the diagnostic yield and complications of transthoracic needle biopsy, reports detailing CT-guided thoracic biopsy in the Thai population remain limited. This study is primarily aimed at evaluating the incidence of pneumothorax and parenchymal haemorrhage after CT-guided transthoracic biopsy and influencing factors that relate to these complications at a single institution. The secondary purpose is to determine the diagnostic accuracy of the biopsy procedure and the rate of diagnostic failure.

\section{Material and methods}

\section{Patient selection}

This study was approved by the Human Ethics Committee of our institute. All biopsy procedures under CT guidance from March 2015 to June 2017 were retrospectively reviewed from the Radiology Information System. The inclusion criteria were patients who underwent TTNB and had available images of the preoperative multidetector computed tomography (MDCT) of the chest on the Picture Archiving and Communication System (PACS) of the hospital. The exclusion criteria were patients who had no CT imaging of the procedure on the PACS or had incomplete procedural data.

\section{Biopsy procedure}

All patients must have acceptable coagulogram before the biopsy procedure. Antiplatelet drugs and anticoagulants were discontinued at least seven days prior the procedure.
Patients were informed about the purpose, process of the biopsy procedure, probability of the complications after the procedure, and the proper management.

TTNBs were performed under CT guidance, using a 128-slice CT system (Somatom Definition AS, Siemens, Berlin and München, Germany) by one of two interventional radiologists (three years' and 13 years' experience in image-guided TTNB). After the operator reviewed the latest CT images and the patient's conditions, the patient was positioned properly. CT scan was obtained to detect the target lesion. The most appropriate and safest pathway to the target lesion was determined. The skin marker was attached to the estimated skin entry site. A CT scan was performed again to establish the exact skin entry site, correlated with the skin marker, and to measure the depth from the skin entry site to the target lesion. The skin marker was then removed, and the skin was prepared using sterile technique, and $1 \%$ lidocaine was used for local anaesthesia. The operator assigned the angle between the needle and the chest wall and then inserted a 19-gauge coaxial introducer pointing the target lesion. After confirming the needle position by repeated CT scanning, a 20-gauge semiautomated cutting needle (Biofeather, Medax Medical Device, Italy) was inserted into the lesion through the coaxial introducer, and the biopsy was performed. The decision to perform CNB only, FNA only, or both CNB and FNA was operator dependent. The tissue obtained from the CNB was then put in the $10 \%$ formalin solution, and the specimen obtained from the FNA was sprayed on to the slide and then placed in the 95\% ethyl alcohol. Some of the specimen was sent as air-dried for additional analysis such as special staining or culture. Immediate postprocedural CT was performed to detect complications.

The patient was observed for any clinical symptoms for at least two hours. Chest radiograph was routinely obtained at two hours after the procedure. In cases of presence of pneumothorax, a subsequent two-hour follow-up radiograph was performed. Patients with minimal pneumothorax or pulmonary haemorrhage without symptoms were advised and then discharged. A drainage catheter was inserted in cases of pneumothorax with symptoms or in cases of progressive pneumothorax on the follow-up imaging, both depending on clinical judgement.

\section{Data collection}

One board-certified interventional radiologist and an attending radiology resident retrospectively reviewed the latest chest CT before the biopsy and the CT of the biopsy procedure. The latest preprocedural chest CT was reviewed in the axial, coronal, and sagittal planes with slice thickness of 2.5-5 mm. The origin of the target lesion, indication of biopsy, lesion size and characteristics, and lesion location were recorded. Lesion size was defined as the mean diameter of the two maximal diameters measured on axial image. 
The CT images of the biopsy procedure were reviewed in the axial plane with a slice thickness of $2.5 \mathrm{~mm}$. The procedural information including the patient's position, depth and angle of the needle path, and emphysema or fissure passed by the needle were documented. The lesion depth was measured from the pleura to the surface of the target lesion along the needle path. The "needle-pleural angle" was defined as the angle between the needle and the line perpendicular to the pleural surface at the needle entry point [8] (Figure 1)

Pneumothorax and pulmonary haemorrhage as well as management were recorded based on the immediate CT after biopsy procedure, the first follow-up chest radiograph, and the medical records. The maximal thickness of the pneumothorax was measured on the immediate post-procedural CT images. Pulmonary haemorrhage was defined as a new consolidative or ground-glass opacity on the post-biopsy imaging along the needle tract or surrounding the lesion, either on CT or chest radiograph. The haemorrhage was classified into two types: type I was haemorrhage along the needle tract and type II was haemorrhage surrounding the pulmonary lesion with or without haemorrhage along the needle tract [11] (Figure 2).

Pathological results from the CNB, cytological results from the FNA, pathological results from the surgical specimen in cases of undergoing surgical resection, the clinical and imaging follow-up, as well as the management of patients with complications after procedures, were obtained from the Hospital Information System.

\section{Assessment of diagnostic accuracy}

The final diagnosis, as the reference, of the target lesion was concluded as one of the three categories as follows: (1) malignancy, (2) benign, and (3) indeterminate. The criteria for malignancy were surgical specimen showing malignancy, pathological result from CNB revealing malignancy, or follow-up imaging showing progression of a pulmonary lesion that was considered to be lung metastasis. The criteria for benignity were surgical specimen showing benignity, pathological result from $\mathrm{CNB}$ revealing benign lesion, or follow-up imaging showing decreased size of the lesion of $20 \%$ or more without any data of treatment of malignancy.

The pathological result from $\mathrm{CNB}$ and the cytological result from FNA were recorded, and then the concordance was determined. The pathological result from CNB was subclassified into five categories as follows: (1) malignancy, (2) specific benign lesion such as haematoma, (3) nonspecific benignity such as granuloma, chronic inflammation, and fibrosis, (4) infection such as tuberculosis, and (5) non-diagnostic result. The cytological result from FNA was classified into three categories as follows: (1) malignancy, and (2) benign and (3) non-diagnostic results. Diagnostic failure was defined as a pathological

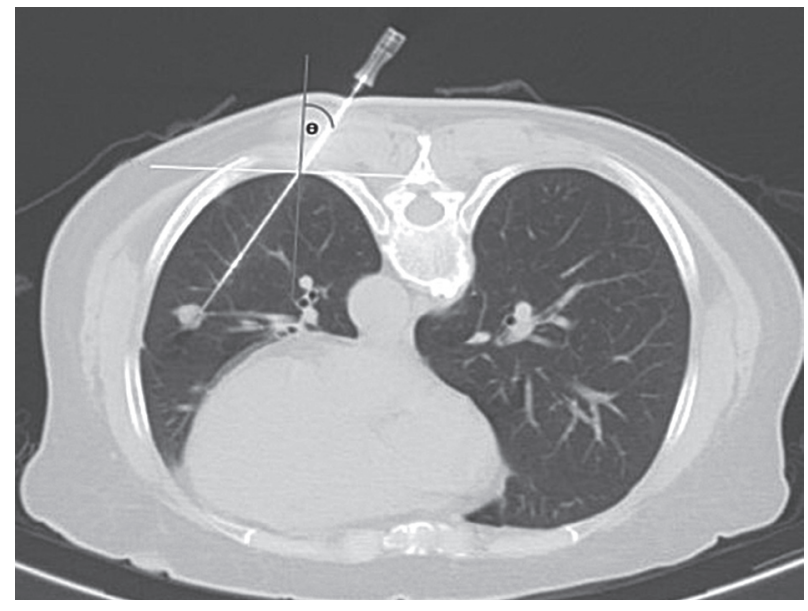

Figure 1. The "needle-pleural angle". Line A was tangential to the pleural surface at the needle entry point. Line $B$ was perpendicular to the line $A$ at the needle entry point. The needle-pleural angle was defined as the angle between the needle and line $B$

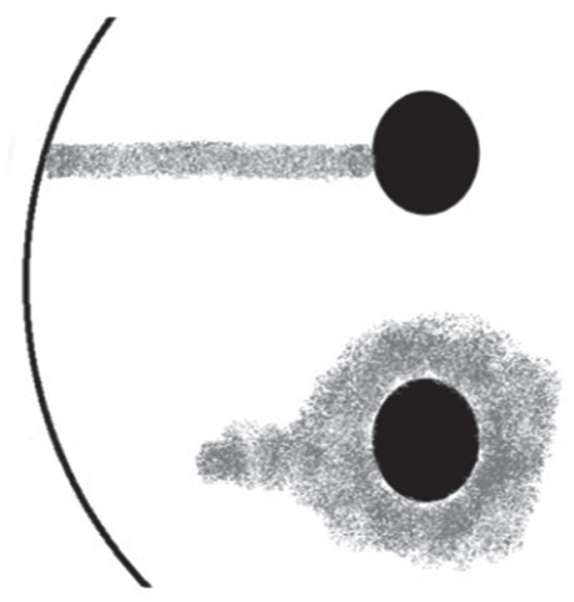

Figure 2. Types of pulmonary haemorrhage. Type I was haemorrhage along the needle tract, type II was haemorrhage surrounding the lesion with or without haemorrhage along the needle tract

result from CNB being non-diagnostic result or revealing a false negative result according to the criteria for malignancy.

\section{Statistical analysis}

SPSS version 23.0 for Windows (SPSS Inc., Chicago, Illinois, USA) was used for statistical analysis. Univariate analysis with $X^{2}$ or Fisher exact test for categorical variables and Student's $t$-test for continuous variables were performed to evaluate whether study variables were significantly different between groups regarding complications of the biopsy procedure. The threshold for statistical significance was set at a $P$ value of less than 0.05 . The sensitivity, specificity, positive predictive values (PPV), negative predictive values (NPV), and accuracy of the CNB and FNA were calculated by using $2 \times 2$ tables. 


\section{Results}

\section{Study population}

From March 2015 to June 2017 there were 216 patients (mean age: $62.6 \pm 14.4$ years, range: 16 to 89 years) undergoing CT-guided TTNB. There were 126 male patients (mean age: $63 \pm 14.6$ years) and 90 female patients (mean age: $62.2 \pm 14.3$ years)

\section{Lesion characteristics}

Biopsies of 194 pulmonary, 13 mediastinal, and nine pleural lesions were performed. Among all pulmonary lesions, there were 153 solid nodules, nine subsolid nodules, 19 consolidations, and 13 cavitary lesions. Indications for lung biopsy were solitary lesion $(n=118,60.8 \%)$, multiple lesions ( $n=64,33.0 \%)$, and focal infiltration $(n=12,6.2 \%)$. The mean size of the pulmonary lesions was $3.1 \pm 2.0 \mathrm{~cm}$ (range: $0.4-10.7 \mathrm{~cm}$ ).
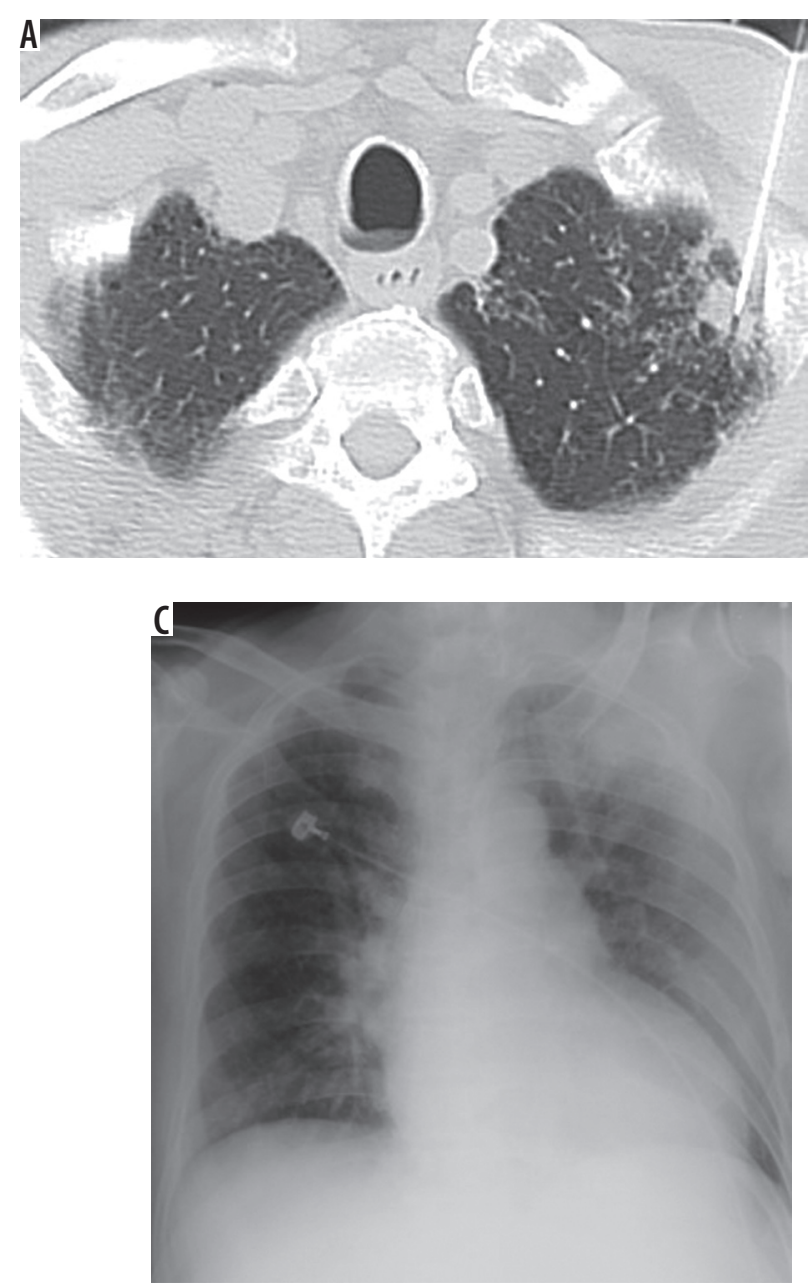

\section{Complications}

Pneumothorax occurred in 50 patients (23.1\%). Among these, there were 11 patients $(22.0 \%$ of patients with pneumothorax and $5.1 \%$ of all procedures) who needed percutaneous drainage. The durations of retaining drainage catheter ranged from two to 30 days (median five days). Two of these 50 patients (4\%) did not have pneumothorax on the immediate CT scan but later developed pneumothorax on the follow-up chest radiograph: one at five hours after the procedure with maximal pneumothorax thickness of $2.1 \mathrm{~cm}$; and the another at two hours after the procedure with maximal pneumothorax thickness of $0.6 \mathrm{~cm}$. None of them required chest drain.

Pulmonary haemorrhage was found in 98 patients (45.4\%), which were classified as type I $(n=29,29.6 \%)$ and type II $(n=69,70.4 \%)$. All had clinical improvement after conservative treatment (Figure 3 ). There were 22 patients $(10.2 \%)$ with both pneumothorax and pulmonary haemorrhage after the procedure. No procedure-related mortality was detected.
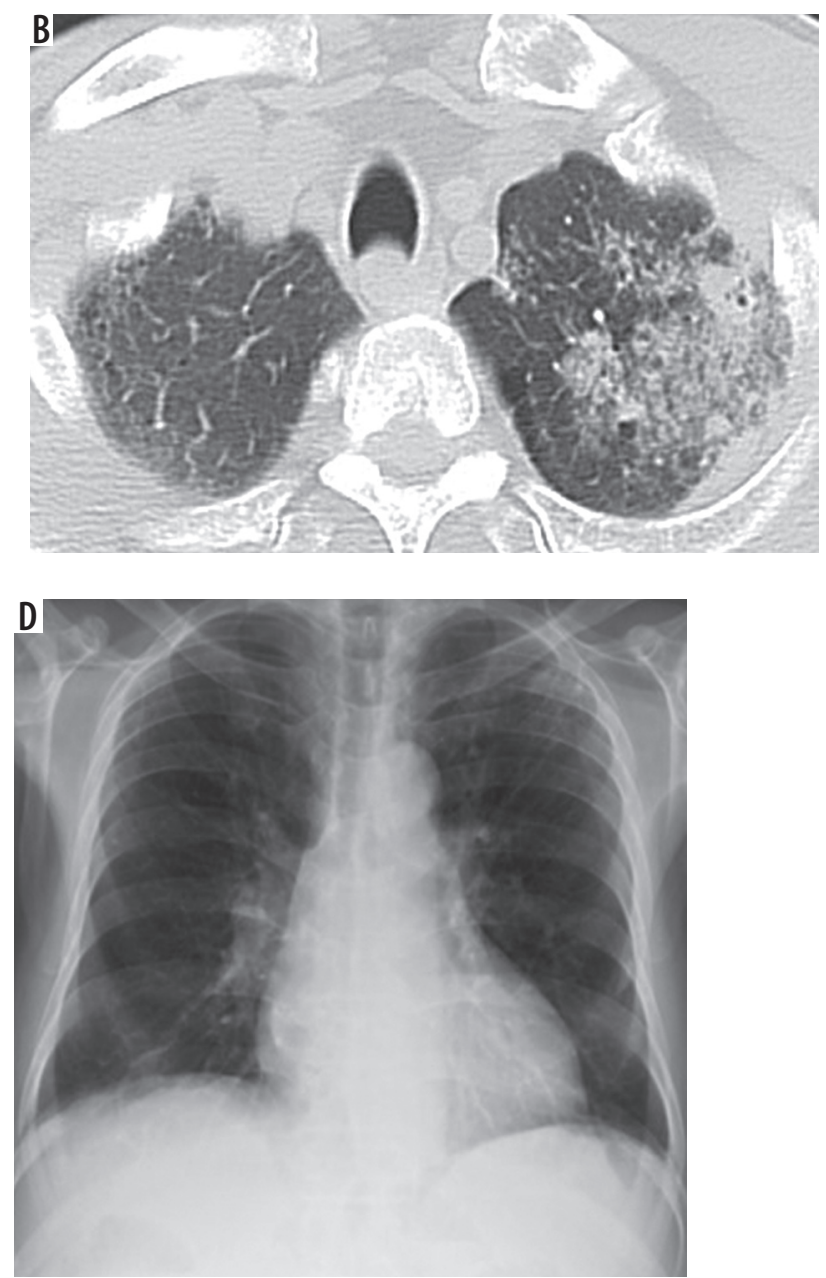

Figure 3. Chest $\mathrm{CT}$ and chest radiograph of a 67 -year-old male with underlying chronic lung disease, who underwent CT-guided lung biopsy of a 1.8-cm nodule at left upper lobe (LUL). A) Chest (T during the procedure. B) Immediate chest (T after the procedure showed pulmonary haemorrhage type II. C) Chest radiograph 2 hours after the procedure showed patchy opacity at LUL, representing pulmonary haemorrhage. The patient had minimal haemoptysis and self-recovery during close clinical observation. One day after biopsy, the patient was discharged. D) Follow-up chest radiograph 2 months after the procedure showed disappearance of the opacity at LUL 


\section{Factors associated with complications}

The incidence of pneumothorax significantly increased in patients with underlying pulmonary infection $(p=0.008)$, small lesion size $(p=0.001)$, and increased needle length traversing lung parenchyma $(p=0.036)$ (Tables 1 and 2). Lesion size of less than $1 \mathrm{~cm}$ showed significantly increased rate of pneumothorax $(p=0.031)$. Conversely, lesion size of more than $3 \mathrm{~cm}$ showed significantly decreased rate of pneumothorax $(p=0.027)$. Pneumothorax was more likely to occur with the needle length traversing lung parenchyma of more than $2 \mathrm{~cm}(p=0.024)$. There was no statistically significant association between the pneumothorax thickness and the need of drainage catheter insertion $(p=0.186)$. However, a significant relation between underlying chronic obstructive pulmonary disease (COPD) and the need for drainage catheter insertion was found $(p=0.009)$ (Figure 4, Table 3).

Higher rate of pulmonary haemorrhage was significantly correlated with underlying malignancy $(p<0.001)$, small lesion size $(p<0.001)$, increased needle length traversing lung parenchyma $(p<0.001)$, and solid nodule $(p<0.001)$. Lesion size of $3 \mathrm{~cm}$ or less and lesion depth of more than $3 \mathrm{~cm}$ revealed significantly increased rate of pulmonary haemorrhage $(p<0.001)$. Patients with consolidative lesion had significantly lower incidence of pulmonary haemorrhage ( $p=0.007)$ (Tables 4 and 5).

\section{Diagnostic accuracy}

Among the total of 216 lesions, 119 were malignancy ( 88 primary lung cancers and 31 lung metastases), 76 were benign (three thymoma, one thymic cyst, one spindle cell tumour, four tuberculosis, four fungal infection, and 63 nonspecific infection and inflammation), and 21 were indeterminate.

The final diagnosis of malignancy was made based on surgical pathology $(n=9)$, specific malignant result from CNB ( $n=103)$, and evidence of progression of the pulmonary lesion on follow-up imaging $(n=7)$. The final diagnosis of benignity was made based on surgical pathology $(n=1)$, specific benign result from $\mathrm{CNB}(n=9)$, and significantly decreased size on the follow-up imaging $(n=66)$.

CNBs were performed in all lesions, whereas FNAs were done in 133 of 216 lesions (61.6\%). Pathological results from CNB were malignancy $(n=112,51.9 \%)$, specific benign result $(n=9,4.1 \%)$, nonspecific benign lesion $(n=71,32.9 \%)$, infection $(n=7,3.2 \%)$, and non-diagnostic result $(n=17,7.9 \%)$. Cytological results from FNA were malignancy $(n=73,54.9 \%)$, benignity $(n=37$, $27.8 \%)$, and non-diagnostic result $(n=23,17.3 \%)$.

There were five false-negative cases in CNB. Sensitivity, specificity, PPV, NPV, and accuracy of the CNB for the diagnosis of malignancy were $95.7 \%, 100 \%, 100 \%, 93.3 \%$, and $97.3 \%$, respectively. There were three false-positive cases and four false-negative cases in FNA. Sensitivity,
Table 1. Univariate analysis of selected variables according to patient and lesion characteristics as risk factors for pneumothorax after CT-guided TTNB $(n=216)$

\begin{tabular}{|c|c|c|c|}
\hline Variables & $\begin{array}{c}\text { With } \\
\text { pneumothorax } \\
(n=50)^{*}\end{array}$ & $\begin{array}{c}\text { Without } \\
\text { pneumothorax } \\
(n=166)^{*}\end{array}$ & Pvalue \\
\hline Gender & & & 0.354 \\
\hline Male & $32(64.0)$ & $94(56.6)$ & \\
\hline Female & $18(36.0)$ & $72(43.4)$ & \\
\hline $\operatorname{Age}(y)^{* *}$ & $63.1 \pm 13.9$ & $62.5 \pm 14.6$ & 0.778 \\
\hline \multicolumn{4}{|l|}{ Underlying disease } \\
\hline COPD & $8(16.0)$ & $20(12.0)$ & 0.466 \\
\hline $\begin{array}{l}\text { Pulmonary } \\
\text { infection }\end{array}$ & $12(24.0)$ & $16(9.6)$ & 0.008 \\
\hline $\begin{array}{l}\text { Chronic lung } \\
\text { disease }\end{array}$ & $5(10.0)$ & $6(3.6)$ & 0.133 \\
\hline $\begin{array}{l}\text { Pulmonary arterial } \\
\text { hypertension }\end{array}$ & $3(6.0)$ & $13(7.8)$ & 1.000 \\
\hline $\begin{array}{l}\text { Pulmonary venous } \\
\text { hypertension }\end{array}$ & $1(2.0)$ & $0(0.0)$ & 0.231 \\
\hline On ventilator & $2(4.0)$ & $0(0.0)$ & 0.053 \\
\hline $\begin{array}{l}\text { Underlying } \\
\text { malignancy }\end{array}$ & $20(40.0)$ & $59(35.5)$ & 0.566 \\
\hline Lesion size $(\mathrm{cm})^{* *}$ & $2.6 \pm 1.5$ & $3.5 \pm 2.2$ & 0.001 \\
\hline Lesion size & & & 0.023 \\
\hline$<1 \mathrm{~cm}$ & $9(18.0)$ & $12(7.2)$ & \\
\hline $1-3 \mathrm{~cm}$ & $24(48.0)$ & $68(41.0)$ & \\
\hline$>3 \mathrm{~cm}$ & $17(34.0)$ & $86(51.8)$ & \\
\hline Lesion depth $(\mathrm{cm})^{* *}$ & $2.5 \pm 1.6$ & $1.9 \pm 1.9$ & 0.050 \\
\hline Lesion depth & & & 0.036 \\
\hline $0 \mathrm{~cm}$ & $5(10.0)$ & $53(31.9)$ & \\
\hline $0.1-1.0 \mathrm{~cm}$ & $6(12.0)$ & $13(7.8)$ & \\
\hline $1.1-2.0 \mathrm{~cm}$ & $12(24.0)$ & $40(24.1)$ & \\
\hline $2.1-3.0 \mathrm{~cm}$ & $7(14.0)$ & $10(6.0)$ & \\
\hline$>3.0 \mathrm{~cm}$ & $20(40.0)$ & $50(30.1)$ & \\
\hline Lesion location $^{* * * *}$ & & & 0.124 \\
\hline RUL & $11(23.4)$ & $49(33.3)$ & \\
\hline RML & $4(8.5)$ & $5(3.4)$ & \\
\hline$\underline{\mathrm{RLL}}$ & $16(34.0)$ & $29(19.7)$ & \\
\hline LUL & $8(17.0)$ & $36(24.5)$ & \\
\hline LLL & $8(17.0)$ & $28(19.0)$ & \\
\hline $\begin{array}{l}\text { Lesion abutting } \\
\text { fissure }\end{array}$ & $11(22.0)$ & $38(22.9)$ & 0.895 \\
\hline
\end{tabular}

*Data are numbers of patients, with percentages in parentheses.

**Data are means \pm standard deviations.

*** Lesion location was analysed only for lesions with pulmonary origin.

CT - computed tomography, TTNB - transthoracic needle biopsy, COPD - chronic obstructive pulmonary disease, RUL - right upper lobe, RML - right middle lobe, RLL - right lower lobe, $\mathrm{LUL}$ - left upper lobe, LLL - left lower lobe 
Table 2. Univariate analysis of selected variables according to biopsy procedure as risk factors for pneumothorax after CT-guided TTNB $(n=216)$

\begin{tabular}{|c|c|c|c|}
\hline Variable & $\begin{array}{c}\text { With } \\
\text { pneumothorax } \\
(n=50)^{*}\end{array}$ & $\begin{array}{c}\text { Without } \\
\text { pneumothorax } \\
(n=166)^{*}\end{array}$ & $P$ value \\
\hline Patient's position & & & 0.573 \\
\hline Supine & $21(42.0)$ & $84(50.6)$ & \\
\hline Prone & $26(52.0)$ & 77 (46.4) & \\
\hline Lateral decubitus & $2(4.0)$ & $4(2.4)$ & \\
\hline Oblique & $1(2.0)$ & $1(0.6)$ & \\
\hline Puncture site & & & 0.511 \\
\hline Anterior & $9(18.0)$ & $44(26.5)$ & \\
\hline Anterolateral & $8(16.0)$ & $31(18.7)$ & \\
\hline Lateral & $5(10.0)$ & $10(6.0)$ & \\
\hline Posterior & $25(50.0)$ & $67(40.4)$ & \\
\hline Posterolateral & $3(6.0)$ & $14(8.4)$ & \\
\hline Needle angle & & & 0.957 \\
\hline$<60^{\circ}$ & $26(52.0)$ & $87(52.4)$ & \\
\hline$>60^{\circ}$ & $24(48.0)$ & $79(47.6)$ & \\
\hline $\begin{array}{l}\text { Emphysema passed } \\
\text { on the needle } \\
\text { pathway }\end{array}$ & $4(8.0)$ & $6(3.6)$ & 0.245 \\
\hline $\begin{array}{l}\text { Fissure passed on the } \\
\text { needle pathway }\end{array}$ & $2(4.0)$ & $4(2.4)$ & 0.625 \\
\hline Biopsy technique & & & 0.510 \\
\hline Core biopsy & $17(34.0)$ & $65(39.2)$ & \\
\hline $\begin{array}{l}\text { Core biopsy with } \\
\text { FNA }\end{array}$ & $33(66.0)$ & $101(60.8)$ & \\
\hline
\end{tabular}

FNA - fine needle aspiration, CT - computed tomography, TTNB - transthoracic needle biopsy

specificity, PPV, NPV, and accuracy of the FNA for the diagnosis of malignancy were $94.4 \%, 90.9 \%, 95.7 \%, 88.2 \%$, and $93.3 \%$, respectively. The concordance between CNB and FNA was 98 of 105 (93.3\%). Seventeen non-diagnostic results and five false-negative results from CNB resulted in a total of $22(10.2 \%)$ cases of diagnostic failure.

\section{Discussion}

In our study, the rate of pulmonary haemorrhage was $45.4 \%$. Although the rate was slightly high, it was comparable with the previous reported rates from two large studies, ranging from $26.8 \%$ to $41.1 \%$ [11,12]. None of these cases needed further intervention. The rates of pneumothorax and chest tube placement for pneumothorax were $23.1 \%$ and $5.1 \%$ of the procedures, respectively. These rates are within the estimated ranges published in Quality improvement guidelines for percutaneous needle biopsy [3], which reported the rate of pneumothorax of $12 \%$ to $45 \%$ and set the threshold for chest tube placement for pneumothorax of $2.0 \%$ to $15.0 \%$. The median duration of
Table 3. Univariate analysis of selected variables as associated factors for retaining drainage catheter in patients with pneumothorax $(n=50)$

\begin{tabular}{|l|c|c|c|}
\hline Variables & $\begin{array}{c}\text { With } \\
\text { drainage } \\
\text { catheter } \\
(n=11)^{*}\end{array}$ & $\begin{array}{c}\text { Without } \\
\text { drainage } \\
\text { catheter } \\
(n=39)^{*}\end{array}$ & Pvalue \\
\hline \begin{tabular}{l} 
Gender \\
\hline Male
\end{tabular} & $9(81.8)$ & $23(59.0)$ & 0.287 \\
\hline Female & $2(18.2)$ & $16(41.0)$ & \\
\hline Age (y) ${ }^{* *}$ & $62.6 \pm 13.5$ & $63.3 \pm 14.1$ & 0.893 \\
\hline \begin{tabular}{l} 
Underlying disease \\
\hline COPD
\end{tabular} & $5(45.5)$ & $3(7.7)$ & 0.009 \\
\hline \begin{tabular}{l} 
Pulmonary infection \\
\hline Chronic lung disease
\end{tabular} & $2(18.2)$ & $10(25.6)$ & 1.000 \\
\hline $\begin{array}{l}\text { Pulmonary arterial } \\
\text { hypertension }\end{array}$ & $1(9.1)$ & $2(5.1)$ & 0.534 \\
\hline $\begin{array}{l}\text { Pulmonary venous } \\
\text { hypertension }\end{array}$ & $0(0.0)$ & $1(2.6)$ & 1.000 \\
\hline On ventilator & $1(9.1)$ & $1(2.6)$ & 0.395 \\
\hline Underlying malignancy & $5(45.5)$ & $15(38.5)$ & 0.736 \\
\hline Lesion size (cm)** & $2.4 \pm 1.5$ & $2.6 \pm 1.5$ & 0.701 \\
\hline Lesion depth (cm)** & $2.6 \pm 1.4$ & $2.5 \pm 1.7$ & 0.861 \\
\hline Lesion abutting fissure & $1(9.1)$ & $10(25.6)$ & 0.416 \\
\hline $\begin{array}{l}\text { Pneumothorax } \\
\text { thickness (cm)** }\end{array}$ & $1.17 \pm 1.17$ & $0.66 \pm 0.51$ & 0.186 \\
\hline
\end{tabular}

COPD - chronic obstructive pulmonary disease

*Data are numbers of patients, with percentages in parentheses.

**Data are means \pm standard deviations.

chest tube insertion in our study was five days (ranging from two to 30 days). We found that patients with underlying COPD who developed pneumothorax after TTNB were more likely to have chest tube drainage insertion ( $p$ $=0.009$ ), which could be explained by increased airway pressure in pulmonary emphysema, resulting in persistent air leakage. Hiraki et al. [13] similarly reported way that pulmonary emphysema and deep lesion significantly increased the rate of chest tube placement for the patient with pneumothorax. Brandén et al. [14] stated a high rate of chest tube insertion (57\% of patients with pneumothorax after TTNB) in patients with $\mathrm{FEV}_{1}<35 \%$.

In this study, we found two out of 216 patients (0.9\%) developed pneumothorax, which was later detected on the follow-up chest radiograph at two hours and five hours. This rate was analogous to the reported rate of delayed pneumothorax, varying from $0.7 \%$ to $3.3 \%[15,16]$. Choi et al. [15] reported that the time of the detection of delayed pneumothorax ranged between five and 120 hours after biopsy, and only $40 \%$ of patients with delayed pneumothorax developed chest symptoms. Previous studies also showed that initial covert pneumothorax sometimes required chest tube insertion [15-18]. Because chest radi- 

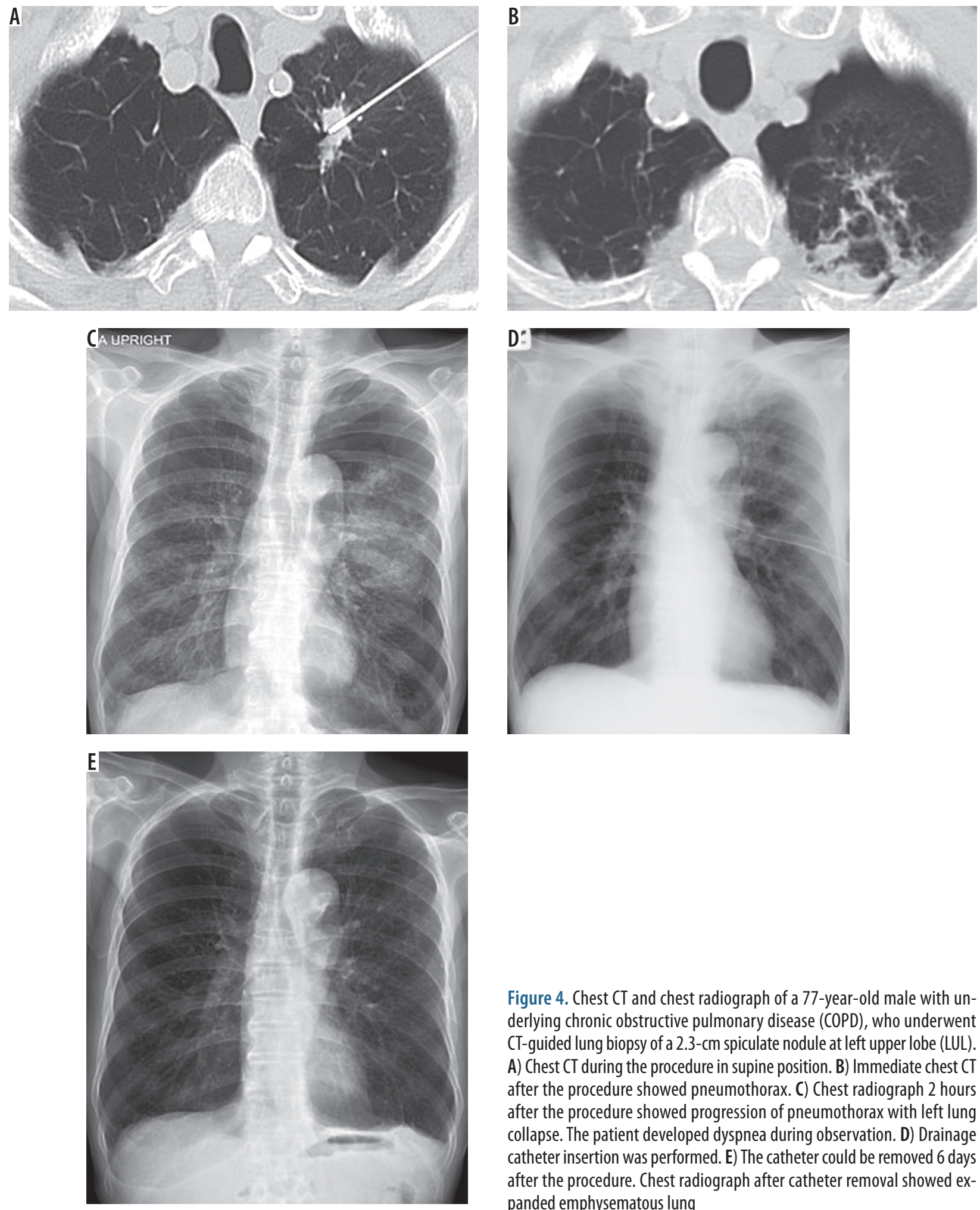

ograph can miss a significant number of pneumothorax cases after CT-guided lung biopsy [18] and some delayed pneumothorax needs further intervention, these can reflect that both immediate $\mathrm{CT}$ after biopsy and follow-up chest radiograph are still necessary. In addition, healthcare providers should inform patients about the symptoms of pneumothorax before discharge, which may help in early detection of delayed pneumothorax.

Figure 4. Chest CT and chest radiograph of a 77-year-old male with underlying chronic obstructive pulmonary disease (COPD), who underwent CT-guided lung biopsy of a 2.3-cm spiculate nodule at left upper lobe (LUL). A) Chest $\mathrm{CT}$ during the procedure in supine position. B) Immediate chest $\mathrm{CT}$ after the procedure showed pneumothorax. C) Chest radiograph 2 hours after the procedure showed progression of pneumothorax with left lung collapse. The patient developed dyspnea during observation. D) Drainage catheter insertion was performed. E) The catheter could be removed 6 days after the procedure. Chest radiograph after catheter removal showed expanded emphysematous lung

Our study showed that needle length traversing lung parenchyma of more than $2 \mathrm{~cm}$, lesion size of less than 1 $\mathrm{cm}$, and underlying pulmonary infection were the significant risk factors of pneumothorax. These could be due to increased difficulty in accurate placement of the needle into a target lesion that was small and deeply located, resulting in an increased number of needle redirections, increased amount of traversed lung parenchyma, or in- 
Table 4. Univariate analysis of selected variables according to patient and lesion characteristics as risk factors for pulmonary hemorrhage after CT-guided TTNB $(n=216)$

\begin{tabular}{|c|c|c|c|}
\hline Variables & $\begin{array}{c}\text { With } \\
\text { parenchymal } \\
\text { hemorrhage } \\
(n=98)^{*}\end{array}$ & $\begin{array}{c}\text { Without } \\
\text { parenchymal } \\
\text { hemorrhage } \\
(n=118)^{*}\end{array}$ & $P$ value \\
\hline Gender & & & 0.548 \\
\hline Male & $55(56.1)$ & $71(60.2)$ & \\
\hline Female & $43(43.9)$ & $47(39.8)$ & \\
\hline $\operatorname{Age}(y)^{* *}$ & $63.7 \pm 12.9$ & $61.8 \pm 15.6$ & 0.332 \\
\hline \multicolumn{4}{|l|}{ Underlying disease } \\
\hline COPD & $16(16.3)$ & $12(10.2)$ & 0.180 \\
\hline $\begin{array}{l}\text { Pulmonary } \\
\text { infection }\end{array}$ & $13(13.3)$ & $15(12.7)$ & 0.904 \\
\hline $\begin{array}{l}\text { Chronic lung } \\
\text { disease } \\
\end{array}$ & $7(7.1)$ & $4(3.4)$ & 0.232 \\
\hline $\begin{array}{l}\text { Pulmonary arterial } \\
\text { hypertension }\end{array}$ & $7(7.1)$ & $9(7.6)$ & 0.892 \\
\hline $\begin{array}{l}\text { Pulmonary venous } \\
\text { hypertension }\end{array}$ & $0(0.0)$ & $1(0.8)$ & 1.000 \\
\hline On ventilator & $1(1.0)$ & $1(0.8)$ & 1.000 \\
\hline $\begin{array}{l}\text { Underlying } \\
\text { malignancy }\end{array}$ & $49(50.0)$ & $30(25.4)$ & $<0.001$ \\
\hline Lesion size $(\mathrm{cm})^{* *}$ & $2.3 \pm 1.6$ & $4.2 \pm 2.1$ & $<0.001$ \\
\hline Lesion size & & & $<0.001$ \\
\hline$<1 \mathrm{~cm}$ & $19(19.4)$ & $2(1.7)$ & \\
\hline $1-3 \mathrm{~cm}$ & $56(57.1)$ & $36(30.5)$ & \\
\hline$>3 \mathrm{~cm}$ & $23(23.5)$ & $80(67.8)$ & \\
\hline Lesion depth $(\mathrm{cm})^{* *}$ & $2.9 \pm 1.8$ & $1.3 \pm 1.5$ & $<0.001$ \\
\hline Lesion depth & & & $<0.001$ \\
\hline $0 \mathrm{~cm}$ & $4(4.1)$ & $54(45.8)$ & \\
\hline $0.1-1.0 \mathrm{~cm}$ & $7(7.1)$ & $12(10.1)$ & \\
\hline $1.1-2.0 \mathrm{~cm}$ & $28(28.6)$ & $24(20.3)$ & \\
\hline $2.1-3.0 \mathrm{~cm}$ & $9(9.2)$ & $8(6.8)$ & \\
\hline$>3.0 \mathrm{~cm}$ & $50(51.0)$ & $20(16.9)$ & \\
\hline Lesion location ${ }^{* * *}$ & & & 0.366 \\
\hline RUL & $28(29.2)$ & $32(32.7)$ & \\
\hline RML & $7(7.3)$ & $2(2.0)$ & \\
\hline RLL & $22(22.9)$ & $23(23.5)$ & \\
\hline$\underline{\text { LUL }}$ & $19(19.8)$ & $25(25.5)$ & \\
\hline LLL & $20(20.8)$ & $16(16.3)$ & \\
\hline $\begin{array}{l}\text { Lesion } \\
\text { characteristics }^{* * *}\end{array}$ & & & $<0.001$ \\
\hline Solid & $81(82.7)$ & $72(61.0)$ & \\
\hline Subsolid & $7(7.1)$ & $2(1.7)$ & \\
\hline Consolidation & $3(3.1)$ & $16(13.6)$ & \\
\hline Cavity & $5(5.1)$ & $8(6.8)$ & \\
\hline
\end{tabular}

*Data are numbers of patients, with percentages in parentheses.

**Data are means \pm standard deviations.

***Lesion location and lesion characteristics were analysed only lesions with pulmonary in origin. CT - computed tomography, TTNB - transthoracic needle biopsy, COPD - chronic obstructive pulmonary disease, RUL - right upper lobe, RML - right middle lobe, RLL - right lower lobe, LUL - left upper lobe, LLL - left lower lobe
Table 5. Univariate analysis of selected variables according to biopsy procedure and final diagnosis as risk factors for pulmonary haemorrhage after CT-guided TTNB $(n=216)$

\begin{tabular}{|l|c|c|c|}
\hline Variables & $\begin{array}{c}\text { With } \\
\text { parenchymal } \\
\text { haemorrhage } \\
(n=98)^{*}\end{array}$ & $\begin{array}{c}\text { Without } \\
\text { parenchymal } \\
\text { haemorrhage } \\
(n=118)^{*}\end{array}$ & P value \\
\hline $\begin{array}{l}\text { Emphysema passed } \\
\text { on the needle } \\
\text { pathway }\end{array}$ & $5(5.1)$ & $1(0.1)$ & 0.095 \\
\hline $\begin{array}{l}\text { Fissure passed on the } \\
\text { needle pathway }\end{array}$ & $7(7.1)$ & $3(2.5)$ & 0.191 \\
\hline \begin{tabular}{l} 
Biopsy technique \\
\hline Core biopsy
\end{tabular} & $37(37.8)$ & $45(38.1)$ & 0.954 \\
\hline $\begin{array}{l}\text { Core biopsy with } \\
\text { FNA }\end{array}$ & $61(62.2)$ & $73(63.5)$ & \\
\hline Final diagnosis & $53(54.1)$ & $66(55.9)$ & \\
\hline Malignancy & $33(33.7)$ & $43(36.4)$ & \\
\hline Benign & $12(12.2)$ & $9(7.6)$ & \\
\hline Unknown & & & \\
\hline
\end{tabular}

*Data are numbers of patients, with percentages in parentheses. FNA - fine needle aspiration

creased dwelling time of the needle. However, there was no recorded data about the number of needle redirections in our study. Patients with underlying pulmonary infection probably could not hold their breath well enough, leading to technical difficulties. The results of our study are in parallel with the large retrospective review by Yeow et al. [9], which stated that a lesion size of $\leq 2 \mathrm{~cm}$ had increased pneumothorax rate. However, they reported that a lesion depth of 0.1 to $2 \mathrm{~cm}$ had higher risk of pneumothorax than a lesion depth of $\geq 2.1 \mathrm{~cm}$. They postulated that biopsy of the subpleural lesion was difficult to perform and suggested that the use of a longer oblique transpulmonary needle path could reduce the risk of pneumothorax. In contrast, other authors who have analysed the depth of the needle path have described an increasing rate of pneumothorax with greater lesion depth $[13,19]$.

To decrease the rates of pneumothorax, Kinoshita et al. [20] suggested that rolling the patient with biopsy site down for 15 minutes, using a special table, could decrease the pneumothorax rate as compared to the standard procedure. Sealing the needle track using autologous blood clot could reduce incidence of pneumothorax and may decrease the severity of pneumothorax [21]. Moreover, the use of CT-fluoroscopy-guided biopsy could provide lower complication rate due to nearly real-time imaging obtained during needle insertion, resulting in shorter procedural time and fewer needle passages $[22,23]$.

For pulmonary haemorrhage, we found that needle length traversing lung parenchyma of more than $3 \mathrm{~cm}$, lesion size of $3 \mathrm{~cm}$ or less, solid lesion, and underlying malignancy were the significant risk factors. These can be 
explained in a similar way to the risk factors of pneumothorax. Patients with underlying malignancy probably had impaired or decreased platelet function due to their previous or on-going treatment and might have had other confounding comorbidities that predispose them to bleeding. Increased sample size with subgroup analysis may prove this hypothesis. The consolidative lesion showed significantly decreased pulmonary haemorrhage, probably because it contained less vascularity and the contents within the air-space may have decreased the potential space for the haemorrhage to expand. Our result is comparable with those in previous literature $[9,12,24]$.

Although we found that none of the patients needed further intervention because it is usually self-limited, and one study reported that the need of hospitalisation for the patients with haemoptysis after TTNB was only $0.4 \%$ [12], patients should be advised to cough to prevent airway obstruction from any blood clots and should be placed in a decubitus position with the biopsy side down to prevent spill of blood into the contralateral lung after needle removal [24].

According to the FNA results in our study, there were four false negative cases. All of them had the final diagnosis of pulmonary metastasis. CNB helped identify the definite diagnosis in three of four cases. There was only one case that had a false negative result from both FNA and $\mathrm{CNB}$, which occurred due to non-targeted biopsy of the $0.6-\mathrm{cm}$ nodule. Among three false positive results of FNA, CNB correctly discovered benignity in two of the three cases. The other had a non-diagnostic result from CNB. The rate of non-diagnostic results from CNB (7.9\%) was also lower than that from FNA (17.3\%). These could imply that CNB is more accurate than FNA, although there was no significant difference in the diagnostic accuracies between FNA and CNB groups. Anderson et al. [25] showed that core biopsy was a more accurate method of tissue sampling than fine needle aspiration and was not associated with an excess of complications. However, the more recent studies state that diagnostic yield is not decreased when using FNA [26], and advances in FNA cytology have enabled subtyping of lung cancer in cytological material [27].

In our study, sensitivity, specificity, PPV, NPV, and accuracy of CT-guided TTNB for the diagnosis of malignancy were $95.7 \%, 100 \%, 100 \%, 93.3 \%$, and $97.3 \%$, respectively. The accuracies of TTNB were $97.0 \%$ for pulmonary lesions, $100 \%$ for mediastinal lesions, and 100\% for pleural lesions. These results are comparable with previous studies [28-33]. We found that the diagnostic accuracy for lesions smaller than $1 \mathrm{~cm}$ was relatively low, at about $88.9 \%$. For lesions larger than $1 \mathrm{~cm}$ the outcome was more favourable, at about $98.2 \%$. This is probably due to the fact that precise placement of the needle in small lesions is more difficult than in large lesions. Fluoro-CT and cone-beam CT guidance seem to increase diagnostic accuracy in small lesions because of the real-time imaging guidance and flexibility in entry site selection $[23,34]$. Choi et al. [35] reported that the use of the aspiration alone was an independent risk factor of diagnostic failure for pulmonary nodules smaller than $1 \mathrm{~cm}$. Two previous studies [36,37] also described the significant difference in accuracy of biopsy of the small subpleural nodules between using the "oblique path" (tangential approach) and right-angle path (direct approach). They demonstrated that the tangential approach had higher accuracy than the direct approach. They postulated that the longer transparenchymal and subcutaneous track offered better needle stability and easier needle redirection without additional violation to the pleura. In our study, we also found that the diagnostic accuracy for the lesions in the lower lobe (94.1\%) was relatively low as compared to the lesions in the upper and middle lobes (99.0\%). It is possible that the lesions in the lower lobe have greater respiratory motion, resulting in increased difficulty in access. An on-site cytopathologist or cytotechnologist, who evaluated the adequacy of the tissue samples, might also help increase the diagnostic yield for the laboriously accessed lesion.

There were some limitations in our study. Firstly, this was a retrospective study, which could have an unknown bias. We could not organise the follow-up protocol and the guideline management of the complications. Secondly, we diagnosed COPD, pulmonary hypertension, and pulmonary infection based only on imaging and medical records. Thirdly, the biopsy techniques and the choice of tissue sampling were based on the operators' consideration, which might affect the diagnostic yield and complications. We believe that further prospective study with standard follow-up protocol would be more beneficial in generating the guideline for follow-up and hospitalisation.

\section{Conclusions}

In conclusion, CT-guided TTNB is a safe procedure and has high diagnostic accuracy. The most common complication is pulmonary haemorrhage. Influencing factors for pneumothorax are underlying pulmonary infection, lesion size less than $1 \mathrm{~cm}$, and lesion depth more than $2 \mathrm{~cm}$. Underlying malignancy, solid pulmonary nodule, lesion size of $3 \mathrm{~cm}$ or less, and lesion depth of more than $3 \mathrm{~cm}$ are associated with pulmonary haemorrhage.

\section{Acknowledgments}

The authors would like to thank Associate Professor Utairat Chaumrattanakul, Department of Radiology, Faculty of Medicine, Thammasat University for editing the English.

\section{Conflict of interest}

The authors report no conflict of interest. 


\section{References}

1. MacMahon H, Naidich DP, Goo JM, et al. Guidelines for management of incidental pulmonary nodules detected on CT Images: From the Fleischner Society 2017. Radiology 2017; 284: 228-243.

2. Winokur RS, Pua BB, Sullivan BW, et al. Percutaneous lung biopsy: technique, efficacy, and complications. Semin Intervent Radiol 2013; 30: 121-127.

3. Gupta S, Wallace MJ, Cardella JF, et al. Quality improvement guidelines for percutaneous needle biopsy. J Vasc Interv Radiol 2010; 21 : 969-975.

4. Heerink WJ, de Bock GH, de Jonge GJ, et al. Complication rates of CT-guided transthoracic lung biopsy: meta-analysis. Eur Radiol 2017; 27: 138-148.

5. Tomiyama N, Yasuhara Y, Nakajima Y, et al. CT-guided needle biopsy of lung lesions: a survey of severe complication based on 9783 biopsies in Japan. Eur J Radiol 2006; 59: 60-64.

6. Ishii H, Hiraki T, Gobara H, et al. Risk factors for systemic air embolism as a complication of percutaneous CT-guided lung biopsy: multicenter case-control study. Cardiovasc Intervent Radiol 2014; 37: 1312-1320.

7. Lorenz J, Bulm M. Complications of percutaneous chest biopsy. Semin Intervent Radiol 2006; 23: 188-193.

8. Lim CS, Tan LE, Wang JY, et al. Risk factors of pneumothorax after CT-guided coaxial cutting needle lung biopsy through aerated versus nonaerated lung. J Vasc Interv Radiol 2014; 25: 1209-1217.

9. Yeow KM, Su IH, Pan KT, et al. Risk factors of pneumothorax and bleeding: multivariate analysis of $660 \mathrm{CT}$-guided coaxial cutting needle lung biopsies. Chest 2004; 126: 748-754.

10. Ko JP, Shepard JO, Drucker EA, et al. Factors influencing pneumothorax rate at lung biopsy: are dwell time and angle of pleural puncture contributing factors? [published erratum appears in Radiology 2001; 220: 556]. Radiology 2001; 218: 491-496.

11. De Filippo M, Saba L, Silva M, et al. CT-guided biopsy of pulmonary nodules: is pulmonary hemorrhage a complication or an advantage? Diagn Interv Radiol 2014; 20: 421-425.

12. Tai R, Dunne RM, Trotman-Dickenson B, et al. Frequency and severity of pulmonary hemorrhage in patients undergoing percutaneous CT-guided transthoracic lung biopsy: single-institution experience of 1175 cases. Radiology 2016; 279: 287-296.

13. Hiraki T, Mimura $\mathrm{H}$, Gobara $\mathrm{H}$, et al. Incidence of and risk factors for pneumothorax and chest tube placement after CT fluoroscopy-guided percutaneous lung biopsy: retrospective analysis of the procedures conducted over a 9-year period. AJR Am J Roentgenol 2010; 194: 809-814.

14. Brandén E, Wallgren S, Högberg H, et al. Computer tomography-guided core biopsies in a county hospital in Sweden: Complication rate and diagnostic yield. Ann Thorac Med 2014; 9: 149-153.

15. Choi CM, Um SW, Yoo CG, et al. Incidence and risk factors of delayed pneumothorax after transthoracic needle biopsy of the lung. Chest 2004; 126: 1516-1521.

16. Pua B, Tang E, Bhat A, et al. Delayed pneumothorax after percutaneous lung biopsy in the state of California. J Vasc Interv Radiol 2016; 27: S90.

17. Noh TJ, Lee CH, Kang YA, et al. Chest computed tomography (CT) immediately after CT-guided transthoracic needle aspiration biopsy as a predictor of overt pneumothorax. Korean J Intern Med 2009; 24: 343-349.

18. Bungay HK, Berger J, Traill ZC, et al. Pneumothorax post CT-guided lung biopsy: a comparison between detection on chest radiographs and CT. Br J Radiol 1999; 72: 1160-1163.
19. Khan MF, Straub R, Moghaddam SR, et al. Variables affecting the risk of pneumothorax and intrapulmonal hemorrhage in CT-guided transthoracic biopsy. Eur Radiol 2008; 18: 1356-1363.

20. Kinoshita F, Kato T, Sugiura K, et al. CT-guided transthoracic needle biopsy using a puncture site-down positioning technique. AJR Am J Roentgenol 2006; 187: 926-932.

21. Lang EK, Ghavami R, Schreiner VC, et al. Autologous blood clot seal to prevent pneumothorax at CT-guided lung biopsy. Radiology 2000; 216: 93-96.

22. Prosch H, Stadler A, Schilling M, et al. CT fluoroscopy-guided vs. multislice CT biopsy mode-guided lung biopsies: accuracy, complications and radiation dose. Eur J Radiol 2012; 81: 1029-1033.

23. Kim GR, Hur J, Lee SM, et al. CT fluoroscopy-guided lung biopsy versus conventional CT-guided lung biopsy: a prospective controlled study to assess radiation doses and diagnostic performance. Eur Radiol 2011; 21: 232-239.

24. Nour-Eldin NE, Alsubhi M, Naguib NN, et al. Risk factor analysis of pulmonary hemorrhage complicating CT-guided lung biopsy in coaxial and non-coaxial core biopsy techniques in 650 patients. Eur J Radiol 2014; 83: 1945-1952.

25. Anderson JM, Murchison J, Patel D. CT-guided lung biopsy: factors influencing diagnostic yield and complication rate. Clin Radiol 2003; 58: 791-797.

26. Moore W, Sawas A, Lee C, et al. Needle gauge and cytological yield in CT-guided lung biopsy. ISRN Pulmonol 2011.

27. Hasanovic A, Rekhtman N, Sigel CS, et al. Advances in fine needle aspiration cytology for the diagnosis of pulmonary carcinoma. Patholog Res Int 2011: 897292.

28. Lee SM, Park CM, Lee KH, et al. C-arm cone-beam CT-guided percutaneous transthoracic needle biopsy of lung nodules: clinical experience in 1108 patients. Radiology 2014; 271: 291-300.

29. Yeow KM, Tsay PK, Cheung YC, et al. Factors affecting diagnostic accuracy of CT-guided coaxial cutting needle lung biopsy: retrospective analysis of 631 procedures. J Vasc Interv Radiol 2003; 14: 581-588.

30. Loh SE, Wu DD, Venkatesh SK, et al. CT-guided thoracic biopsy: evaluating diagnostic yield and complications. Ann Acad Med Singapore 2013; 42: 285-290.

31. Geraghty PR, Kee ST, McFarlane G, et al. CT-guided transthoracic needle aspiration biopsy of pulmonary nodules: needle size and pneumothorax rate. Radiology 2003; 229: 475-481.

32. Montaudon M, Latrabe V, Pariente A, et al. Factors influencing accuracy of CT-guided percutaneous biopsies of pulmonary lesions. Eur Radiol 2004; 14: 1234-1240.

33. Hiraki T, Mimura H, Gobara H, et al. CT fluoroscopy-guided biopsy of 1,000 pulmonary lesions performed with 20-gauge coaxial cutting needles: diagnostic yield and risk factors for diagnostic failure. Chest 2009; 136: 1612-1617.

34. Rotolo N, Floridi C, Imperatori A, et al. Comparison of cone-beam CT-guided and CT fluoroscopy-guided transthoracic needle biopsy of lung nodules. Eur Radiol 2016; 26: 381-389.

35. Choi SH, Chae EJ, Kim JE, et al. Percutaneous CT-guided aspiration and core biopsy of pulmonary nodules smaller than $1 \mathrm{~cm}$ : analysis of outcomes of 305 procedures from a tertiary referral center. AJR Am J Roentgenol 2013; 201: 964-970.

36. Wallace MJ, Krishnamurthy S, Broemeling LD, et al. CT-guided percutaneous fine-needle aspiration biopsy of small $(<$ or $=1-\mathrm{cm})$ pulmonary lesions. Radiology 2002; 225: 823-828.

37. Tanaka J, Sonomura T, Shioyama Y, et al. "Oblique path" - the optimal needle path for computed tomography-guided biopsy of small subpleural lesions. Cardiovasc Intervent Radiol 1996; 19: 332-334. 